\title{
OS REQUISITOS DE PROJETO EM CONTEXTO DE PANDEMIA: UMA DISCUSSÃO SOBRE OS ESPAÇOS DE ENSINO EM UNIVERSIDADES PÚBLICAS
}

\author{
DESIGN REQUIREMENTS IN THE PANDEMIC CONTEXT: A DISCUSSION ABOUT \\ EDUCATIONAL SPACES IN PUBLIC UNIVERSITIES
}

\author{
Renata Soares Faria ${ }^{1}$, Paulo Roberto Pereira Andery ${ }^{2}$
}

\section{RESUMO:}

O ano de 2020 ficará marcado, entre muitos eventos, pela pandemia que impactou várias dimensões da vida. O Ministério da Educação lançou em julho de 2020 o primeiro protocolo de biossegurança para retorno das atividades presenciais. O objetivo deste trabalho foi analisar, à luz dos primeiros protocolos de segurança emitidos por órgãos públicos, que diretrizes poderão ser utilizadas para desenvolvimento de requisitos que comporão os programas de necessidades dos projetos arquitetônicos, com ênfase em espaços de ensino de instituições públicas de ensino superior. Analisa-se como essas diretrizes poderão ser incorporadas às soluções arquitetônicas do ponto de vista do uso ou operação dos espaços. O marco metodológico foi estudo de caso, com ênfase em análise documental. Foram analisados o Protocolo do Ministério da Educação Brasileiro, Protocolo das Universidades Federal de Minas Gerais - Brasil, Universidade Estadual de Campinas - Brasil e Universidade do Porto - Portugal. Após as análises individuais, foi feita uma comparação entre os mesmos. As análises mostram que as medidas buscam a redução de risco associado ao contato entre pessoas e entre pessoas e superfícies contaminadas, e são em sua maioria requisitos comportamentais e relacionados ao uso e ocupação. Nota-se que requisitos funcionais e de habitabilidade poderão orientar decisões futuras de projeto. O fato de a pandemia estar em andamento, inclusive em 2021, torna difícil concluir sobre os impactos na forma de projetar. Contudo, não diminui a importância de aproveitar-se a oportunidade para discutir o impacto dessas questões de biossegurança na determinação e desenvolvimento de requisitos de projeto nos projetos arquitetônicos.

PALAVRAS-CHAVE: biossegurança; pandemia; requisitos de projeto; projeto para o desempenho.

\section{ABSTRACT:}

The year 2020 will be marked, among many events, by the pandemic that impacted various dimensions of life. In July 2020, the Ministry of Education launched the first biosafety protocol for returning to face-to-face activities. The objective of this work was to analyze, in the light of the security protocols issued by public agencies, which guidelines can be used to develop requirements that will compose the programs of architectural projects, with an emphasis on teaching spaces of public universities. It analyzes how these guidelines can be incorporated into architectural solutions from the point of view of the use or operation of spaces. The methodological was a case study, with an emphasis on documentary analysis. The Protocol of the Brazilian Ministry of Education, Protocol of the Federal Universities of Minas Gerais -Brazil, State University of Campinas - Brazil and University of Porto - Portugal were analyzed. After the individual analyzes, a comparison was made between them. The analyzes show that the measures seek to reduce the risk associated with contact between people and between people and contaminated surfaces, and are mostly behavioral requirements related to use and occupation. It is noted that functional and habitability requirements may guide future design decisions. The fact that the pandemic is underway, including 2021, makes it difficult to conclude about the impacts on the way of projecting. However, the importance of taking the opportunity to discuss the impact of these biosafety issues on determining and developing design requirements in architectural projects does not diminish.

KEYWORDS: biosecurity; pandemia; design briefing; performance-based design. .

How to cite this article:

FARIA, R.S., ANDERY, P.R.P.. Os requisitos de projeto em contexto de pandemia: uma discussão sobre os espaços de ensino em instituições públicas. Gestão \& Tecnologia de Projetos. São Carlos, v16, n4, 2021. https://doi.org/10.11606/gtp.v16i4.178073

${ }^{1}$ Universidade Federal de Viçosa, Brasil.

2Universidade Federal de Minas Gerais, Brasil.

Fonte de Financiamento: Fundação de Amparo à Pesquisa do Estado de Minas Gerais.

Conflito de Interesse: Um dos autores é editor associado da revista.

Ética em Pesquisa:

Não se aplica.

Submetido em: 11/11/2020

Aceito em:

18/09/2021 


\section{INTRODUÇÃO}

Sabe-se que o desenvolvimento dos projetos de arquitetura insere-se em um contexto vital. Conforme afirmam Duarte e Noronha (2011, p. 4): "a obra de arquitetura incorpora as vicissitudes do trajeto, os acasos das mudanças de rumo [...], o atravessamento de multiplicidades na qual o acidente configura em uma realidade existencial". A arquitetura possui uma natureza de transformação, durante o uso dos espaços são naturais mudanças que os tornem mais adequados às exigências e solicitações de desempenho do seu contexto e ocupantes. Requisitos de desempenho são por vezes determinados durante o desenvolvimento do programa estratégico ou funcional dos empreendimentos, ou até mesmo durante o desenvolvimento dos projetos, e são decorrentes de novos fatos, contextos ou circunstâncias, particularmente em ambientes de incerteza e complexidade.

0 ano de 2020 foi especialmente desafiador no que se refere as expectativas de segurança e qualidade do espaço construído. No dia 11 de março de 2020 a Organização Mundial de Saúde (OMS) elevou o estado da contaminação de COVID-19 ao status de pandemia. Em função do risco, atividades que contribuam para a convivência de um maior número de pessoas foram paralisadas ou sofreram alterações significativas em sua condução. Em resposta ao risco, o governo brasileiro publicou no dia 07 de fevereiro de 2020 a Lei no 13.979 , que dispõe sobre as medidas para enfrentamento da emergência de saúde pública de importância internacional decorrente do coronavírus responsável pelo surto de 2020. Desde essa publicação, foram emitidas outras regulamentações a respeito do enfrentamento ao COVID-19. No âmbito da educação podemos citar especificamente o Parecer CNE/CP no 5/2020, com orientações com vistas à reorganização do calendário escolar, a Medida Provisória no 934, de $1^{\text {o }}$ de abril de 2020, estabelecendo normas excepcionais sobre o ano letivo, a Portaria no 544, de 16 de junho de 2020 que dispôs sobre a substituição das aulas presenciais por aulas em meios digitais, enquanto durar a situação de pandemia do novo coronavírus- COVID-19.

É necessário evidenciar a realidade bastante dinâmica da pandemia. Já avançado o ano de 2020, houve mudanças nas práticas de trabalho para que algumas modalidades não adaptáveis ao regime remoto fossem realizadas, contudo com o agravamento da pandemia em 2021, algumas instituições retornaram aos estágios mais iniciais dos planos de retomada, adotando medidas mais restritivas; como pode-se ver na nota a comunidade vinculada no site da UFMG:

Desde odia 12 de marçodo corrente ano, a UFMG, diante do recrudescimento da pandemia de covid-19, retrocedeu à etapa zero do seu Plano de Retorno e acompanha aevolução do cenárioregional e nacional.o quadro epidemiológico no Brasil permanece grave e instável com média de 45 mil novos casos confirmados de covid-19e 2 mil óbitos por dia (UFMG, 2021).

Portanto, faz-se necessário destacar que ao longo da pandemia foram publicados distintos documentos e atualizações dos mesmos, havendo espaço ainda para que até o final desta pandemia mais atualizações sejam feitas. Contudo, sublinha-se que há um sombreamento entre os documentos, que mantem sua linha dorsal inalterada pautada em conceitos de biossegurança básicos e essencialmente voltados ao distanciamento social e medidas de proteção individual como uso máscaras.

Nesta conjuntura, a biossegurança passa a ser um conceito cada vez mais recorrente. Conceituando-a:

A biossegurança pode ser definida como o conjunto de ações voltadas para a prevenção, minimização ou eliminação de riscos inerentes às atividades de 
pesquisa, produção, ensino, desenvolvimento tecnológico e prestação de serviços, visando à saúde do homem, dos animais, à preservação do meio ambiente e à qualidade dos resultados (SANGIONI et al., 2013, p.91).

Papu e Pal (2020) lembram que, historicamente, a arquitetura e o planejamento urbanos já responderam a problemas sanitários. Os autores pontuam que as cidades, através de seus desenhos de ruas, sistemas de esgoto e leis de zoneamento, testemunham de como a arquitetura e o planejamento urbano incorporaram preocupações de saúde pública, historicamente, em resposta à miséria urbana e a outros eventos epidêmicos como cólera, gripe e tuberculose. Nessa mesma lógica, a relação entre segurança sanitária e arquitetura fica mais evidente. Desdobrando o conceito de biossegurança tem-se:

Os seus princípios começam a ser incorporados modificando concepções espaciais, de materiais de acabamento, mobiliários, tratamento, renovação do ar e diferenciais de pressão, para minimizar os eventuais riscos ambientais que possam estar presentes, exigindo um esforço conjunto por parte dos profissionais envolvidos, de modo a estabelecer, no projeto arquitetônico, padrões e normas que assegurem a qualidade ambiental, com o cumprimento das condições de segurança necessárias (COHEN et al., 2019.p. 1196.)

Deste sombreamento entre arquitetura e biossegurança, percebe-se que os requisitos dos projetos não se referem apenas às organizações espaciais, mas também aos efeitos da construção sob seus usuários. Destacam-se os requisitos relacionados à habitabilidade da construção, que trata da condição que o ambiente possui de ser habitável de modo seguro e confortável, para seu usuário. Exemplos de requisitos de habitabilidade são o desempenho térmico, acústico, lumínico, higiene e qualidade do ar, funcionalidade e acessibilidade. Portanto, os protocolos de biossegurança somam-se a outras categorias de requisitos e estipulam metas específicas de desempenho.

Quanto a ambientes universitários, há muitos aspectos a serem considerados, são muitos espaços para usos e públicos específicos e o aumento de especificidades agrega mais dificuldade em identificar e padronizar, quando conveniente, requisitos de projeto. A isso se somam as características peculiares do processo de projeto em instituições públicas de ensino, elencadas em alguns trabalhos da literatura (ANDERY; STARLING; MARTINS, 2015; COUTINHO e LIMA, 2009; ESTEVES, 2013; ESTEVES e FALCOSKI, 2013, MOTTA, 2003). Contudo, há menos publicações focadas nos requisitos de projetos destes espaços, particularmente considerando questões de biossegurança e habitabilidade, como indicado acima.

O COVID -19 possui inúmeras repercussões no ambiente construído. Na condição de adaptação dos espaços existentes, alguns aspectos são mais adaptáveis que outros. Analisando os protocolos e documentos emitidos de instituições relevantes, é possível mapear critérios e avaliar suas condições de adaptabilidade. Essa análise da capacidade de transformação dos espaços é fundamental para os processos de resposta ao COVID-19, mas também pode fomentar discussões para futuros projetos, aos quais poderemos atribuir mais requisitos com foco em biossegurança, ou valorizar mais requisitos que possuam maior impactos na qualidade sanitária.

O objetivo deste trabalho foi analisar, à luz de alguns dos primeiros protocolos de segurança emitidos por órgãos públicos, que diretrizes poderão ser incorporadas para desenvolvimento de requisitos que comporão os programas de necessidades dos projetos arquitetônicos, com ênfase em espaços de ensino de instituições públicas de ensino superior, bem como como essas diretrizes poderão ser incorporadas às soluções arquitetônicas do ponto de vista do uso ou operação dos espaços. 


\section{FUNDAMENTAÇÃO TEÓRICA}

A biossegurança, segundo Segata (2020), é um campo que aglutina muitas áreas do conhecimento, cuja origem não é completamente clara, mas que atualmente incorpora áreas como ecologia, a epidemiologia, a biotecnologia, a bioética, e as humanidades, focando a contenção de riscos associados a exposições a agentes biológicos.

Quanto à arquitetura, a biossegurança possui muitos desdobramentos sobre o espaço. Cohen et al. (2019) destacam que além da concepção e organização espacial, questões como mobiliário, materiais de acabamento e qualidade do ar interna possuem impacto direto no risco ambiental. Um exemplo do impacto dos protocolos de biossegurança sobre a arquitetura é a normatização rígida para ambientes de saúde e laboratoriais. Nestes ambientes, independente de um contexto pandêmico, há um controle rigoroso dos riscos biológicos, por isso o funcionamento de tais espaços está associado ao atendimento de um conjunto rígidos de normas sanitárias, Simas e Cardoso (2008) sublinham esse aspecto.

Mas, segundo diversos autores, a pandemia trouxe não somente a necessidade de repensar espaços, mas também rever formas de convivência em sociedade, nas suas distintas escalas. Carabia (2020) cunhou o termo "covidtação", uma contração das palavras coabitação e COVID, como que para sublinhar que a pandemia está trazendo um repensar sobre as formas de conviver, não só em nível das habitações, mas em distintas escalas, repensando responsabilidades e prioridades nas definições dos programas de necessidades dos empreendimentos e nos critérios de configuração urbana (ALRAOUF, 2021; SAADAT, RANTANI e HUSSAIN, 2020).

Na mesma linha de raciocínio, Veronese (2020) sugere que sejam sistematicamente incorporados conceitos sobre estudos sobre a proximidade entre pessoas - uma análise proxêmica - redefinindo conceitos sobre espaços comunitários, em um enfoque claramente transdisciplinar, que incorpore conceitos de sociologia e antropologia. Pensamento análogo é apresentado por Mehta (2020), que sugere que a arquitetura pós COVID-19 deve redefinir escalas de proximidade entre as pessoas, e inclusive estabelecer novos critérios de socialização.

Megahed e Ghoneim (2020) ressaltam como critérios para o desenvolvimento de projetos arquitetônicos orientados a aumentar a segurança contra o COVID-19: a) consideração nas soluções arquitetônicas de novas configurações de layout de mobiliário e estações de trabalho; b) rever a forma de compartilhamento de serviços e instalações; c) diminuir a densidade de ocupação dos espaços; d) utilização de materiais que facilitem as condições de higiene, particularmente no caso de superfícies sujeitas ao contato de pessoas. Na mesma linha de outros autores, ressaltam a necessidade de soluções nos projetos de arquitetura e instalações que priorizem a ventilação para melhoria da qualidade interna do ar.

Takewaki (2020) ressalta a necessidade de incorporar o conceito de que aspecto fundamental da arquitetura orientada ao aumento da resiliência é assegurar as condições de biossegurança em condições de pandemia. Ou seja, o conceito de resiliência passa a incorporar a ideia de adaptabilidade das edificações para operar em condições de pandemia. Entre os aspectos de resiliência consideram-se pontos como a) soluções arquitetônicas e estruturais que permitam aumentar a flexibilidade e disposição dos espaços; b) disposição funcional de modo a prevenir contato próximo entre pessoas nos momentos de circulação; c) b) planejamento das condições de ventilação

Na linha de melhorar a qualidade interna do ar, como condição essencial para diminuir os riscos de contágio, Megahe e Ghoneim (2021) propõem uma estrutura conceitual que oriente os critérios de desenvolvimento de projetos arquitetônicos, bem como os protocolos de 
operação das edificações. Esses autores ressaltam a necessidade de se utilizar um enfoque multidisciplinar, que integre a adoção de mecanismos de monitoramento e controle previstos nos projetos de engenharia associados a soluções nos projetos de arquitetura e instalações que reduzam a carga de agentes patogênicos no ar, por meio de especificações para os sistemas de ventilação e condicionamento do ar, incluindo condições de limpeza e exaustão.

No âmbito da operação das edificações, os mesmos autores ressaltam a necessidade de criar e implementar controles administrativos, disponibilizar equipamentos de proteção individual e em especial, a reconfiguração de espaços funcionais, incluindo disposição e utilização de equipamentos e mobiliários.

O estabelecimento de novas condições de operação, associados ao "repensar" das soluções arquitetônicas, é ressaltado por Melone e Bongo (2020), que sugerem a definição de meta regras para o projeto dos espaços e especificação das condições de uso, que inclui não somente a reconfiguração arquitetônica, mas também a criação de mobiliários com design que iniba a proximidade entre pessoas, utilização de paredes móveis que deixem de ter função estrutural e outras medidas para aumentar a flexibilidade dos ambientes.

A gestão dos ativos (edifícios e instalações) é ressaltada por outros autores. Falorud (2020) ressalta a necessidade de criar protocolos de operação das edificações em situações emergenciais, com diretrizes que sejam integradas ao um plano geral de gestão e operação de ativos.

Aspectos como definição de afastamentos mínimos entre pessoas, reconfiguração do compartilhamento de recursos, redução das taxas de ocupação de escritórios para valores em torno de 25 a 30\%, reconfiguração do layout de mobiliário, como já comentado anteriormente, uso de entradas livres nos ambientes ou fechaduras comandadas por voz ou software, são algumas das medidas propostas por Parker (2020). A conscientização das pessoas, por meio de planos de comunicação e treinamento também é enfatizada pelo mesmo autor.

No âmbito das universidades, as transformações no uso dos espaços passaram por significativas mudanças. Com a pandemia de COVID-19, ambientes como sala de aula, outrora seguros, passam ser espaços de risco e por isso, há necessidade de protocolos que garantam condições de uso com segurança.

No caso específico das instituições universitárias, ainda são relativamente poucos os estudos publicados sobre o tema. Izumi et al. (2021) conduziram um survey abrangendo 65 instituições universitárias em 29 países. Entre as conclusões, os autores identificaram a ausência, em grande parcela das instituições, de planos para a continuidade das operações em condições de emergência sanitária, incluindo a análise de riscos potenciais e respostas a distintas situações de risco.

Ressaltando a dificuldade de criação de protocolos gerais - cada instituição deve criar um plano condizente com suas características de funcionamento e condições sanitárias - os autores estabelecem algumas diretrizes gerais, das quais se destacam: a) a clara definição de autoridades para a tomada de decisões, hierarquias e reponsabilidades; b) o estabelecimento de road maps com distintas etapas, dependendo do nível de riscos sanitários; c) o estabelecimento de métodos de comunicação no âmbito da comunidade acadêmica; d) o planejamento e utilização de múltiplos métodos educacionais, com as correspondentes ferramentas didáticas informatizadas; e) a criação de um comitê central para gerenciamento da situação de emergência; f) a apropriação de recursos econômicos a serem utilizados nessas situações especiais, considerando inclusive eventuais mudanças no fluxo de receitas.

Nesse contexto fica claro que requisitos de biossegurança particularizam um subconjunto de requisitos específicos para a edificação, é preciso uma estrutura conceitual para abordar a determinação desses requisitos e o seu tratamento ao longo do processo de projeto. 
Projetar para o atendimento de requisitos de desempenho, o que pode incluir aspectos associados a funcionalidade e biossegurança, não é algo novo. Segundo Gibson (1982), trata-se da prática de pensar e trabalhar em termos de fins e não de meios, ou seja, enfatizando os indicadores de desempenho, sem prescrever soluções projetuais, conforme indicado na estrutura conceitual do Performance Based Building (PBB). O PBB é uma estrutura de desenvolvimento de projetos que prioriza o desempenho alvo necessário para atender às necessidades dos usuários, abordando, portanto, a definição desde o início do processo dos requisitos e suas métricas, sendo necessário processo de validação final. Enfatiza-se a antecipação do desempenho em uso, orientando as decisões desde o início do processo de projeto para garantir a assertividade do desempenho do produto final (FOLIENTE,2000; BAKENS, 2005, SZIGETI e JASUJA, 2005).

Para adequar-se a estrutura do PBB é necessário definir uma sequência de atividades para o processo de projeto. Nesse caso as soluções de projeto partem dos requisitos considerando-os, portanto, entradas do processo. Essas soluções são desenvolvidas e validadas ao longo do processo de projeto por meio de fases bem definidas. Seguindo tal lógica, é necessário destacar que alguns modelos da literatura já indicam essas fases, de maneira detalhada, como é o caso Romano (2006) e Sinduscon (2016). Um maior detalhamento das fases do processo de projeto, desdobrando em soluções os requisitos de desempenho identificado no início do processo, foge do escopo do presente trabalho. Os modelos supracitados não foram preparados especificamente para a questão da pandemia, mas respondem à lógica do processo de projeto baseado em requisitos de desempenho, podendo, portanto, ser utilizados para o tratamento de um amplo grupo de requisitos, nos quais se inserem os requisitos específicos de biossegurança.

Ressalta-se, assim, que anterior à tradução do requisito em solução projetual, uma atividade essencial é a identificação desses requisitos. Para mapeamento de potenciais requisitos de projeto, uma fonte importante de dados são as normas, leis e documentos reguladores. Neste momento atípico e temporário, os protocolos de biossegurança emitidos cumprem, em certa medida, essa função orientadora. Portanto, ainda que não especifiquem como alcançar a segurança e qualidade, a análise destes documentos essencialmente fomentará as fases iniciais do projeto com requisitos de biossegurança.

\section{MÉTODO}

O trabalho tem seu foco na análise - a luz dos recentes protocolos de biossegurança para a situação de pandemia - de possíveis diretrizes para o processo de projeto de espaço de ensino em instituições universitárias públicas. Sob essa ótica, o marco metodológico enquadra-se em pesquisa de natureza aplicada, com abordagem qualitativa e objetivos exploratórios (SILVA E MENEZES, 2005). Como ressaltado por Yin (2010), o propósito do estudo de caso é investigar com profundidade um fenômeno contemporâneo dentro de seu contexto e realidade. As etapas do trabalho foram:

a) definição do problema de pesquisa;

b) realização de revisão bibliográfica específica. Os tópicos destacados foram arquitetura orientada a biossegurança, particularmente na recente situação de pandemia, e conceitos associados a projetos orientados ao desempenho (Performance Based Design), uma vez que requisitos de biossegurança em situação de pandemia foram considerados como uma categoria específica de requisites de desempenho, assim como o são a funcionalidade dos espaços ou os requisitos de habitabilidade (conforto, segurança estrutural, etc.).

c) Seleção de protocolos de biossegurança para análise. Os critérios para seleção foram disponibilidade de informações, adequação ao objeto de estudo (espaços de ensino em 
instituições públicas de nível superior) e grau de detalhamento das informações contidas. Nesse sentido, foram definidos os seguintes protocolos: Protocolo do Ministério da Educação do Governo Brasileiro, Protocolo da Universidade Federal de Minas Gerais - Brasil e Protocolo da Universidade do Porto - Portugal.

d) Análise dos protocolos, triangulação de dados e análise.

As principais fontes de evidências utilizadas na pesquisa foram: os protocolos e documentos publicados em canais oficiais do Ministério da Educação, pela Universidade Federal de Minas Gerais, Universidade Estadual de Campinas e pela Universidade do Porto. Foi realizada uma análise de cada documento separadamente e análise entre documentos, que definirão sobreposições entre as recomendações.

\section{RESULTADOS E DISCUSSÃO}

Para entender os requisitos de projetos em contexto de pandemia, é pertinente analisar os protocolos de segurança como documentos orientadores. 0 protocolo de referência é o do Ministério da Educação Brasileiro (MEC), emitido em julho de 2020, que enumera 70 recomendações, destas, 24 (36\%) impactam o ambiente construído. Em sintonia, compara-se com os protocolos da Universidade Federal de Minas Gerais (UFMG) com 66 recomendações e da Universidade Estadual de Campinas (UNICAMP) com 114 recomendações. Por se tratar de uma pandemia diferentes países, é pertinente analisar também documentos emitidos por instituições internacionais. E neste caso, recorre-se ao documento emitido pela Universidade do Porto (UPorto). A Tabela 01 apresenta uma síntese das principais providências indicadas.

\begin{tabular}{|c|c|c|c|c|c|}
\hline $\begin{array}{l}\text { 옴 } \\
\text { जั } \\
\text { 。̛ }\end{array}$ & MEC & UFMG & U. PORTO & UNICAMP & $\begin{array}{l}\text { REQUISITO } \\
\text { DE PROJETO }\end{array}$ \\
\hline 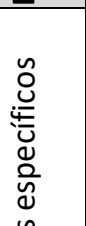 & $\begin{array}{c}\text { Áreas para re- } \\
\text { tirada e descarte } \\
\text { dos equipamentos } \\
\text { de proteção indi- } \\
\text { vidual }\end{array}$ & Contempla & Não contempla & Contempla & $\begin{array}{c}\text { Área para } \\
\text { descarte de } \\
\text { material } \\
\text { contaminate }\end{array}$ \\
\hline 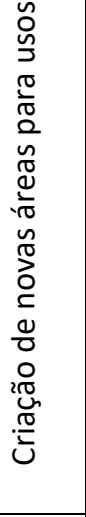 & Não contempla & Não contempla & $\begin{array}{l}\text { As áreas de iso- } \\
\text { lamento devem } \\
\text { ter ventilação } \\
\text { natural, ou } \\
\text { mecânica, re- } \\
\text { vestimentos lisos } \\
\text { e serem bem } \\
\text { equipada. Devem } \\
\text { existir uma ou } \\
\text { mais áreas por } \\
\text { edifício com } \\
\text { acesso fácil. }\end{array}$ & $\begin{array}{l}\text { Não contem- } \\
\text { pla }\end{array}$ & - \\
\hline 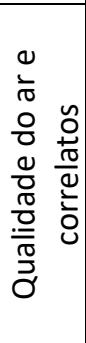 & $\begin{array}{l}\text { Manter, sempre } \\
\text { que possível, } \\
\text { portas e janelas } \\
\text { abertas para } \\
\text { ventilação do } \\
\text { ambiente }\end{array}$ & Contempla & $\begin{array}{l}\text { Contempla e } \\
\text { acrescenta que } \\
\text { pode ser utilizada } \\
\text { a ventilação } \\
\text { mecânica com } \\
\text { cuidados específi- } \\
\text { cos. Prevê inter- }\end{array}$ & $\begin{array}{l}\text { Contempla e } \\
\text { acrescenta } \\
\text { que pode ser } \\
\text { utilizada a } \\
\text { ventilação } \\
\text { mecânica com } \\
\text { cuidados es- } \\
\text { pecíficos }\end{array}$ & $\begin{array}{l}\text { Qualidade } \\
\text { do ar }\end{array}$ \\
\hline
\end{tabular}

Tabela 1. Itens de recomendação do protocolo de segurança

Fonte: Elaborado pelos autores, 2020. 


\begin{tabular}{|c|c|c|c|c|c|}
\hline & & & $\begin{array}{l}\text { valos para venti- } \\
\text { lação dos espa- } \\
\text { ços. E recomenda } \\
\text { ao menos } 6 \text { reno- } \\
\text { vações por hora. }\end{array}$ & & \\
\hline & - & $\begin{array}{c}\text { Considerar a } \\
\text { conformação de } \\
\text { "espaços } \\
\text { acadêmicos pro- } \\
\text { visórios”, prefer- } \\
\text { encialmente nos } \\
\text { espaços abertos } \\
\text { ou muito bem } \\
\text { ventilados. } \\
\text { Deverão verificar } \\
\text { se tais espaços } \\
\text { são estrutural- } \\
\text { mente ade- } \\
\text { quados. }\end{array}$ & Não contempla & $\begin{array}{c}\text { Não contem- } \\
\text { pla }\end{array}$ & $\begin{array}{l}\text { Qualidade } \\
\text { do ar, Con- } \\
\text { forto } \\
\text { Térmico. } \\
\text { layout } \\
\text { flexível e cir- } \\
\text { culação ade- } \\
\text { quada ao } \\
\text { espa- } \\
\text { çamento mí- } \\
\text { nimo exi- } \\
\text { gido. }\end{array}$ \\
\hline \multirow{3}{*}{ 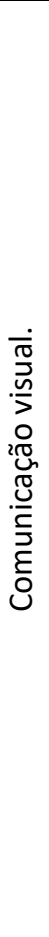 } & $\begin{array}{l}\text { Garantir adequada } \\
\text { comunicação vis- } \\
\text { ual de proteção e } \\
\text { prevenção de } \\
\text { risco. }\end{array}$ & Contempla & Contempla & Contempla & $\begin{array}{l}\text { Posiciona- } \\
\text { mento, } \\
\text { clareza e vis- } \\
\text { ibilidade da } \\
\text { comuni- } \\
\text { cação visual. }\end{array}$ \\
\hline & $\begin{array}{l}\text { Elaborar peças de } \\
\text { comunicação in- } \\
\text { stitucional volta- } \\
\text { das à ressaltando } \\
\text { as principais me- } \\
\text { didas e cuidados } \\
\text { necessários; pro- } \\
\text { porcionar in- } \\
\text { formações nos } \\
\text { sites da instituição }\end{array}$ & Não contempla & Contempla & Contempla & $\begin{array}{l}\text { Posiciona- } \\
\text { mento, } \\
\text { clareza e vis- } \\
\text { ibilidade da } \\
\text { comuni- } \\
\text { cação visual. }\end{array}$ \\
\hline & $\begin{array}{l}\text { Divulgar as orien- } \\
\text { tações sobre o uso } \\
\text { correto de másca- } \\
\text { ras e medidas de } \\
\text { prevenção. }\end{array}$ & Contempla & Contempla & Contempla & $\begin{array}{l}\text { Posiciona- } \\
\text { mento, } \\
\text { clareza e vis- } \\
\text { ibilidade da } \\
\text { comuni- } \\
\text { cação visual. }\end{array}$ \\
\hline \multirow{2}{*}{ 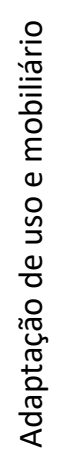 } & Não contempla & Não contempla & $\begin{array}{l}\text { As principais por- } \\
\text { tas de acesso aos } \\
\text { edifícios devem } \\
\text { ser mantidas } \\
\text { abertas ou serem } \\
\text { facilmente } \\
\text { acionáveis. }\end{array}$ & $\begin{array}{c}\text { Não contem- } \\
\text { pla }\end{array}$ & $\begin{array}{l}\text { Adaptação } \\
\text { no uso de } \\
\text { mobiliário }\end{array}$ \\
\hline & Não contempla & Não contempla & $\begin{array}{l}\text { Nos locais de } \\
\text { atendimento com } \\
\text { funcionamento } \\
\text { presencial deve }\end{array}$ & Contempla & $\begin{array}{l}\text { Adaptação } \\
\text { no uso de } \\
\text { mobiliário }\end{array}$ \\
\hline
\end{tabular}




\begin{tabular}{|c|c|c|c|c|c|}
\hline & & & $\begin{array}{l}\text { ser criada barreira } \\
\text { física de acrílico } \\
\text { ou vidro. Deve-se } \\
\text { disponibilizar } \\
\text { solução antissép- } \\
\text { tica e realizar } \\
\text { marcação de dis- } \\
\text { tanciamento no } \\
\text { piso. }\end{array}$ & & \\
\hline & $\begin{array}{l}\text { Cuidados no uso } \\
\text { de bebedouros }\end{array}$ & $\begin{array}{l}\text { Contempla dis- } \\
\text { tanciamento, e } \\
\text { estipula a inter- } \\
\text { dição dos equi- } \\
\text { pamentos. }\end{array}$ & Contempla & $\begin{array}{c}\text { Contempla. E } \\
\text { define que se- } \\
\text { jam lacradas } \\
\text { as torneiras a } \\
\text { jato, de forma } \\
\text { que se possi- } \\
\text { bilite retirada } \\
\text { de água } \\
\text { apenas em } \\
\text { copos des- } \\
\text { cartáveis ou } \\
\text { copos de uso } \\
\text { individual; }\end{array}$ & $\begin{array}{l}\text { Adaptação } \\
\text { no uso de } \\
\text { mobiliário }\end{array}$ \\
\hline \multirow{4}{*}{ 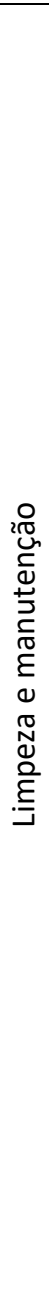 } & $\begin{array}{l}\text { Organizar a rotina } \\
\text { de limpeza do am- } \\
\text { biente de trabalho } \\
\text { e dos equipamen- } \\
\text { tos de uso individ- } \\
\text { ual, bem como lo- } \\
\text { cais de maior fluxo } \\
\text { de pessoas. }\end{array}$ & Contempla & Contempla & $\begin{array}{l}\text { Contempla e } \\
\text { define con- } \\
\text { dições para } \\
\text { ambientes } \\
\text { como por ex- } \\
\text { emplo banhei- } \\
\text { ros que devem } \\
\text { ser higieniza- } \\
\text { dos antes da } \\
\text { abertura, após } \\
\text { o fechamento } \\
\text { e, no mínimo, } \\
\text { a cada três } \\
\text { horas, con- } \\
\text { forme o fluxo } \\
\text { de uso. }\end{array}$ & $\begin{array}{c}\text { Facilidade } \\
\text { de limpeza e } \\
\text { manutenção } \\
\text { das super- } \\
\text { fícies }\end{array}$ \\
\hline & $\begin{array}{l}\text { Manter a limpeza } \\
\text { das salas e auditó- } \\
\text { rios a cada troca } \\
\text { de turma. }\end{array}$ & Contempla & Contempla & Contempla & $\begin{array}{c}\text { Facilidade } \\
\text { de limpeza e } \\
\text { manutenção } \\
\text { das super- } \\
\text { fícies }\end{array}$ \\
\hline & $\begin{array}{c}\text { Manter a limpeza } \\
\text { e desinfecção do } \\
\text { ambiente a cada } 2 \\
\text { horas. }\end{array}$ & $\begin{array}{l}\text { Contempla, mas } \\
\text { não define } \\
\text { período de } \\
\text { horas. }\end{array}$ & $\begin{array}{l}\text { Contempla, mas } \\
\text { não define } \\
\text { período de horas. }\end{array}$ & Contempla & $\begin{array}{c}\text { Facilidade } \\
\text { de limpeza e } \\
\text { manutenção } \\
\text { das super- } \\
\text { fícies }\end{array}$ \\
\hline & $\begin{array}{l}\text { Manter a limpeza } \\
\text { e desinfecção de } \\
\text { equipamentos e } \\
\text { maquinários cole- }\end{array}$ & Contempla & Contempla & Contempla & $\begin{array}{l}\text { Facilidade } \\
\text { de limpeza e } \\
\text { manutenção } \\
\text { das super- } \\
\text { fícies }\end{array}$ \\
\hline
\end{tabular}




\begin{tabular}{|c|c|c|c|c|c|}
\hline & $\begin{array}{c}\text { tivos após a uti- } \\
\text { lização por } \\
\text { usuário. }\end{array}$ & & & & \\
\hline \multirow{5}{*}{ 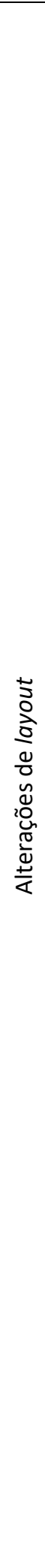 } & Não contempla & $\begin{array}{l}\text { Recomendar que } \\
\text { os elevadores } \\
\text { não sejam uti- } \\
\text { lizados. Incen- } \\
\text { tivar o uso de es- } \\
\text { cadas e o uso } \\
\text { dos espaços dos } \\
\text { pavimentos mais } \\
\text { baixos. }\end{array}$ & Contempla & Contempla & $\begin{array}{l}\text { Layout } \\
\text { flexível e cir- } \\
\text { culação ade- } \\
\text { quada ao } \\
\text { espa- } \\
\text { çamento mí- } \\
\text { nimo exi- } \\
\text { gido }\end{array}$ \\
\hline & Não contempla & $\begin{array}{l}\text { Propor criação } \\
\text { de salas de aula } \\
\text { ao ar livre com } \\
\text { estrutura mínima } \\
\text { necessária para } \\
\text { desenvolvimento } \\
\text { das atividades. }\end{array}$ & Não contempla & $\begin{array}{l}\text { Não contem- } \\
\text { pla }\end{array}$ & $\begin{array}{l}\text { Layout } \\
\text { flexível e cir- } \\
\text { culação ade- } \\
\text { quada ao } \\
\text { espa- } \\
\text { çamento mí- } \\
\text { nimo exi- } \\
\text { gido }\end{array}$ \\
\hline & Não contempla & Não contempla & Não contempla & $\begin{array}{c}\text { Revisão de } \\
\text { layouts deve } \\
\text { ser feita nos } \\
\text { ambientes de } \\
\text { estudo (salas } \\
\text { de aula, la- } \\
\text { boratórios) } \\
\text { para garantir } \\
\text { distancia- } \\
\text { mento social e } \\
\text { eliminação } \\
\text { do acesso a } \\
\text { espaços de } \\
\text { maior aglom- } \\
\text { eração }\end{array}$ & $\begin{array}{l}\text { Layout } \\
\text { flexível e cir- } \\
\text { culação ade- } \\
\text { quada ao } \\
\text { espa- } \\
\text { çamento mí- } \\
\text { nimo exi- } \\
\text { gido }\end{array}$ \\
\hline & Não contempla & $\begin{array}{l}\text { Indicar o sentido } \\
\text { de circulação de } \\
\text { pessoas, mão e } \\
\text { contramão, por } \\
\text { meio de marca- } \\
\text { ções no piso. }\end{array}$ & Contempla. & Contempla & $\begin{array}{l}\text { Layout } \\
\text { flexível e cir- } \\
\text { culação ade- } \\
\text { quada ao } \\
\text { espa- } \\
\text { çamento mí- } \\
\text { nimo exi- } \\
\text { gido } \\
\end{array}$ \\
\hline & $\begin{array}{l}\text { Respeitar o distan- } \\
\text { ciamento de pelo } \\
\text { menos } 1,5 \mathrm{~m} \text { (um } \\
\text { metro e meio) en- } \\
\text { tre pessoas; }\end{array}$ & $\begin{array}{l}\text { Contempla dis- } \\
\text { tanciamento, } \\
\text { mas estipula } 2 \mathrm{~m} \\
\text { como mínimo. }\end{array}$ & $\begin{array}{l}\text { Contempla, mas } \\
\text { aceita } 1 \mathrm{~m} \text { em } \\
\text { salas de aula. E } \\
2 \mathrm{~m} \text { para bibli- } \\
\text { otecas sem in- } \\
\text { stalação de bar- } \\
\text { reira físicas e en- } \\
\text { tre camas nos } \\
\text { dormitórios. }\end{array}$ & $\begin{array}{c}\text { Contempla, } \\
\text { mas estipula } \\
2 \text { m para áreas } \\
\text { de pratica es- } \\
\text { portiva. }\end{array}$ & $\begin{array}{l}\text { Layout } \\
\text { flexível e cir- } \\
\text { culação ade- } \\
\text { quada ao } \\
\text { espa- } \\
\text { çamento mí- } \\
\text { nimo exi- } \\
\text { gido }\end{array}$ \\
\hline
\end{tabular}




\begin{tabular}{|c|c|c|c|c|c|}
\hline \multirow{6}{*}{ 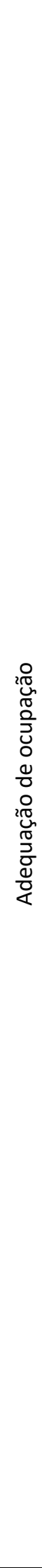 } & Não contempla & $\begin{array}{c}\text { Evitar a realiza- } \\
\text { ção de eventos e } \\
\text { reuniões presen- } \\
\text { ciais não essenci- } \\
\text { ais. } \\
\end{array}$ & $\begin{array}{l}\text { Condiciona os } \\
\text { eventos às nor- } \\
\text { mas vigentes sem } \\
\text { detalhar. }\end{array}$ & Contempla & $\begin{array}{l}\text { Adequação } \\
\text { de ocupação }\end{array}$ \\
\hline & Não contempla & $\begin{array}{c}\text { Estabelecer, se } \\
\text { necessário, rodí- } \\
\text { zios de dias para } \\
\text { a ocupação das } \\
\text { salas de aula e } \\
\text { escalas de horá- } \\
\text { rio. }\end{array}$ & Não contempla & $\begin{array}{c}\text { Recomenda } \\
\text { que atividades } \\
\text { presenciais } \\
\text { devem inicial- } \\
\text { mente conter } \\
\text { número } \\
\text { reduzido } \\
\text { de alunos. } \\
\text { mas não } \\
\text { desenvolve se } \\
\text { será por } \\
\text { rodízio ou } \\
\text { outro método. } \\
\text { Cita o rodízio } \\
\text { para espaços } \\
\text { esportivos. }\end{array}$ & $\begin{array}{l}\text { Adequação } \\
\text { de ocupação }\end{array}$ \\
\hline & Não contempla & $\begin{array}{c}\text { Evitar, sempre } \\
\text { que possível, a } \\
\text { mistura de tur- } \\
\text { mas, trocas de } \\
\text { salas entre tur- } \\
\text { mas, comparti- } \\
\text { Ihamento de ma- } \\
\text { teriais e equi- } \\
\text { pamentos. } \\
\end{array}$ & Não contempla & - & $\begin{array}{l}\text { Adequação } \\
\text { de ocupação }\end{array}$ \\
\hline & Não contempla & $\begin{array}{c}\text { Organizar os ho- } \\
\text { rários de } \\
\text { maneira a re- } \\
\text { duzir o contato } \\
\text { entre grupos } \\
\text { diferentes de es- } \\
\text { tudantes; } \\
\end{array}$ & Não contempla & $\begin{array}{c}\text { Contempla } \\
\text { para laborató- } \\
\text { rios. }\end{array}$ & $\begin{array}{l}\text { Adequação } \\
\text { de ocupação }\end{array}$ \\
\hline & Não contempla & $\begin{array}{l}\text { Considerar a pos- } \\
\text { sibilidade de } \\
\text { adotar escalo- } \\
\text { namento de ho- } \\
\text { rários para en- } \\
\text { tradas, saídas e } \\
\text { intervalos; } \\
\end{array}$ & Não contempla & $\begin{array}{l}\text { Contempla } \\
\text { para espaços } \\
\text { de atividade } \\
\text { esportiva. }\end{array}$ & $\begin{array}{l}\text { Adequação } \\
\text { de ocupação }\end{array}$ \\
\hline & Não contempla & $\begin{array}{c}\text { Aumentar a vari- } \\
\text { abilidade de ho- } \\
\text { rário entre } \\
\text { períodos e/ou } \\
\text { cursos para re- } \\
\text { duzir o uso sim- } \\
\text { ultâneo das de- } \\
\text { pendências. } \\
\end{array}$ & Não contempla & $\begin{array}{l}\text { Não contem- } \\
\text { pla }\end{array}$ & $\begin{array}{l}\text { Adequação } \\
\text { de ocupação }\end{array}$ \\
\hline
\end{tabular}


Como mostra a tabela, as recomendações mudam, mas os requisitos de projeto repetem-se de um item para o outro, sendo recorrentemente ligados à limpeza, organização e flexibilidade de layout e qualidade do ar. Confirmando isso, os protocolos da universidade paulista, por exemplo, tratam como aspectos críticos: 1. Distância e interação entre as pessoas; 2 . Cuidados para manter mãos e superfícies higienizadas e 3. Condições de ventilação. Já o documento da universidade portuguesa decreta que "Qualquer espaço que não cumpra os requisitos relativos ao distanciamento, ventilação ou higienização não deve ser utilizado." (UNIVERSIDADE DO PORTO, 2020, p.11). Embora o segundo tópico (cuidados com as mãos e higienização de superfícies) possa parecer pouco relacionado ao ambiente construído, a limpeza na verdade possui direta relação as superfícies, e neste ponto, a determinação de acabamentos durante o projeto pode impactar diretamente no desempenho deste requisito e na qualidade do espaço construído.

Os requisitos podem ser divididos em três subcategorias: requisitos relativos à forma de utilização dos espaços, mas sem impacto em alterações das condições do espaço construído, requisitos que exigem adaptação ou modificação do espaço construído e requisitos que são diretamente ligados à solução arquitetônica a ser implementada.

A maioria dos requisitos pertence à primeira subcategoria e são mais direcionados ao comportamento dos usuários, principalmente os relativos à limpeza, ainda que o requisito de limpeza tenha desdobramentos importantes principalmente na especificação dos acabamentos superficiais. Dos requisitos que se relacionam ao espaço construído os que requerem adaptação estão mais ligados a flexibilização de layout, adequação de densidade ocupacional e comunicação visual. Já a ventilação tem impacto no espaço construído e tem menor condições de modificação e adaptação, esses requisitos estão diretamente ligados a solução arquitetônica.

Com relação a limpeza, a recomendação possui três desdobramentos principais: uso e disponibilidade de materiais de limpeza, ações do usuário em praticar a higienização do local e a facilidade de limpeza do material superficial e acesso a todas as áreas. 0 último item está diretamente associado às especificações de materiais do ambiente: pisos, paredes, mobiliários, guarda-corpos durante o projeto. Já a acessibilidade às áreas está diretamente ligada às soluções de projeto.

Portanto, este item é estratégico e deve ser necessariamente considerado na concepção e reformulações dos ambientes. Neste ponto o atual espaço construído pode criar forte barreira à adequação para uso. Uma decisão que negligencie a operação do edifício pode criar problemas com soluções que só serão possíveis com uma mudança estruturante nas configurações do espaço, tais como mudanças de acabamento, mudança de layout fixos ou um acréscimo no custo operacional.

Outra consideração importante é que especificar as condições de operação e manutenção dos espaços segue a linha conceitual preconizada na NBR 15.575:2013, que embora trate do desempenho da construção habitacional, aborda conceitualmente questões relacionadas a operação e uso dos edifícios, conceitos esses aplicáveis a outros tipos de edificação, uma vez que tal aspectos estão diretamente relacionados ao desempenho esperado para a mesma.

0 segundo item, organização e flexibilidade de layout, diz respeito à flexibilidade do ambiente em termos da organização e ocupação do espaço. Neste caso, o projeto deverá incorporar previamente questões que acentuem o caráter evolutivo da edificação especificando-se os detalhes construtivos que sejam compatíveis com possíveis projetos para ampliação ou requalificação. Neste caso, são mais críticos ambientes cujos layout são fixos. Assim com o item anterior, a flexibilização quando não planejada, compromete a adaptabilidade ao contexto de pandemia. 
Já a qualidade do ar associa-se às trocas de ar e uma consequência dessa recomendação é o dimensionamento e especificações das esquadrias. Soma-se ainda a questão dos ambientes que fazem uso de equipamentos de resfriamento artificiais, e que eventualmente limitam as trocas de ar em função do conforto térmico. E neste último caso, a recomendação de não se usar tais sistemas, embora atenda ao aspecto sanitário, pode gerar problemas de conforto térmico aos usuários. Mostrando como em condições entrelaçadas, um requisito pode impactar diretamente alguns sistemas e indiretamente outros. Portanto, a complexidade envolvida, demanda cuidados no processo de projeto.

A análise das recomendações mostra que embora os itens que impactam diretamente o ambiente construído não sejam maioria, ainda sim, são críticos e inclusive podem inviabilizar o uso do espaço com segurança. Há ainda que se considerar que ambientes como laboratórios, que possuem atividades específicas precisam ser analisados separadamente, tal como espaços que atendem metodologias de ensino específicas.

0 maior detalhamento é fundamental pra desdobrar recomendações em requisitos objetivos. A Universidade do Porto avança nesse sentido e possui maior detalhamento quanto a espaços funcionais específicos, como auditórios, salas e bibliotecas. Mas não há detalhamentos para ambientes especiais como laboratórios, cujo layout tende a possuir características técnicas restritas às atividades. Faz referência a outros protocolos que foram emitidos tais como as orientações da Direção Geral de Saúde, quanto à metodologia, materiais, produtos e frequência de limpeza, mostrando uma orientação menos generalista e mais prática. Quanto às especificidades, a UFMG abre espaço para a criação de novos espaços acadêmicos temporários que deverão:

1. Possuir grandes aberturas laterais para ventilação cruzada, podendo ser considerados os espaços com delimitados por elementos vazados (cobogós);

2. Possuir cobertura para promover sombreamento adequado às pessoas e aos assentos;

\section{Apresentar condições de acessibilidade (boa pavimentação e} rampas);

4. Atender ao índice máximo de ocupação, considerados os afastamentos mínimos de $2 \mathrm{~m}$ entre as pessoas;

5. A ocupação dos espaços abertos ou livres deve respeitar e garantir áreas de passagens e circulação que permitam aos transeuntes manter a distância mínima (UFMG, 2020, p. 12, grifo nosso).

Considerando os espaços acadêmicos temporários, a citação sinaliza o peso de determinados requisitos de projeto na concepção dos novos espaços, como os demarcados pelo grifo dos autores. Alguns como acessibilidade, sem impacto sanitário, mas condizente ao uso público universitário. Seguindo com as especificidades, é importante destacar que o documento emitido pela Universidade do Porto apresenta como primeiro anexo as "Recomendações às Instituições Científicas e de Ensino Superior para a preparação do Ano Letivo 2020/2021" emitidas pelo Ministério Português da Ciência, Tecnologia e Ensino Superior. Do qual destacase:

Adequem a duração de cada aula e das atividades de avaliação dos estudantes, sempre que tal se revele conveniente e necessário, garantindo a renovação adequada do ar e arejamento das salas, de modo a promover a 
supressão de pausas letivas potencialmente potenciadoras de ajuntamentos em espaços fechados. (UNIVERSIDADE DO PORTO, 2020, p.25).

Neste caso, nota-se que as próprias metodologias de ensino passam por reformulações originadas de possíveis limitadores de qualidade e capacidade de conforto do espaço.

\section{ANÁLISE DOS PROTOCOLOS}

Compilando os quatro documentos, nota-se que os requisitos de projeto se sobrepõem e em sua maioria não são requisitos inovadores. 0 que muda é o fator de importância que esses requisitos assumiram em um contexto de risco sanitário. É possível afirmar que as questões de biossegurança relacionadas à pandemia apresentam um subgrupo de requisitos de projeto que incluem:

I. Facilidade de limpeza e higienização: condições para manutenção da limpeza e calendário para limpeza

a. Garantia da especificação de materiais superficiais de fácil manutenção

b. Definição de um calendário e o procedimento padrão para limpeza deve ser estipulado de forma a garantir a correta higienização e o menor impacto na vida útil.

II. Desempenho Mínimo da Qualidade do Ar Interior: o projeto deve oferecer soluções que eliminem os riscos de contaminação por agentes internos ou externos ao ambiente. Favorecimento do aproveitamento de ventilação natural.

III. Flexibilidade e adaptabilidade de layout: 0 projeto não deve oferecer resistência, ou oferecer o mínimo possível, a mudanças eventuais no espaço, sejam alterações em layout, mobiliário ou equipamentos. Além disso, é importante que o projeto ofereça as informações necessárias para o usuário para que em caso de alterações que seja possível realizá-las respeitando os condicionantes existentes.

Com base na natureza dos requisitos citados, fica evidente o impacto da habitabilidade; e manifesta que projetos cujo programas de necessidades iniciais abordem apenas requisitos funcionais, não atenderão ao desempenho esperado. A predominância de recomendações voltadas ao uso evidencia que para futuros projetos é imperativo que os requisitos de desempenho incorporem tratativas relacionadas ao uso, decompondo questões de uso como limpeza, durabilidade e manutenção em requisitos específicos a serem traduzidos em soluções arquitetônicas.

Contudo, precisa-se destacar que os protocolos são documentos para usos temporários e possivelmente atuarão apenas durante esse período de tempo. Para além disso, discuti-los é pertinente, pois o impacto da pandemia já produz questionamentos e ensaios que questionam o modo de fazer e o papel da arquitetura.

Para além dos protocolos, autores como Papu e Pal (2020 p.1) afirmam: "Sustentabilidade e resiliência da comunidade, em termos socioeconômicos-ambientais globais, parecem ser as únicas lógicas sobreviventes nessas circunstâncias surreais.". Os mesmos autores ainda lançam a ideia de que talvez estejamos construindo muito, sem pensar em formas de otimizar as estruturas já existentes e resguardar os recursos ainda disponíveis. A sustentabilidade que já paira sobre as discussões de arquitetura a alguns anos, tende a ganhar ainda mais força. A flexibilidade dos novos projetos, como forma de otimização de recursos também é um elemento a ser assimilado em futuras soluções arquitetônicas.

As tecnologias, tão importantes em tempo de distanciamentos sociais. Também serão entradas de projetos fundamentais. 0 trabalho remoto e as salas de aula difusas em vários espaços, 
mudaram nossa forma de aprender e forçaram a repensar os modelos pedagógicos. Papu e Pal (2020) afirmam que neste novo contexto, esses locais de aprendizagem, mais do que os prédios físicos, tornam-se portais de conhecimento.

No que diz respeito ao desdobramento dos requisitos definidos ao longo do processo ao processo de projeto, uma forma de aplicar o PBB é primeiramente orientar o processo de projeto enfatizando a fase de programa de necessidades. Isso implica em garantir que o máximo de informações seja levantada e tratada desde as fases iniciais. Com base nos modelos citados neste trabalho, sugere-se que o programa inclua uma declaração de escopo com definição de requisitos, valores meta e forma de avaliação.

No PBB, os requisitos são desdobrados em critérios, e uma vez definidos os critérios, que estabelecem as metas de atendimento ao requisito, são estabelecidas as formas de sua avaliação ou verificação do atendimento. No caso de requisitos de biossegurança, parte dos requisitos já incorpora o critério de aceitação, ou seja, a definição do requisito já implica em uma meta explicitada. Mas, será importante definir a sua forma de avaliação, na etapa inicial de formulação do requisito. Essa forma de avaliação será implementada por análises críticas de projeto ou simulações e/ou ensaios nas edificações construídas.

Sugere-se que o desenvolvimento dos projetos se oriente pela estrutura apresentada pelo Manual para contratação de projetos para o desempenho de edificações habitacionais (SINDUSCON, 2016). Ainda que o documento tenha foco nas edificações habitacionais, sua transferência para tipologias não habitacionais é viável. Embora o referencial seja anterior ao contexto pandêmico, seu uso é viável para desenvolvimento de projetos voltados a desempenho; em uma pandemia, a diferença é que o desempenho passa a estar fortemente ligado a biossegurança e à segurança dos ocupantes do espaço.

\section{CONCLUSÕES}

0 fato de a pandemia ser algo ainda em andamento, torna mais difícil discutir os impactos que eventualmente mudam a forma de projetar os espaços. Tratando dos espaços acadêmicos, é importante dizer que a complexidade do programa de necessidades, torna difícil estabelecer recomendações generalistas, tais como de alguns protocolos emitidos.

Longe de esgotar as discussões, o artigo apresenta uma contribuição para que sejam discutidos os requisitos de desempenho de ambientes universitários, e acrescenta que estruturas conceituais como PBB, possuem um potencial para inovação na forma de projetar.

É possível que surjam camadas de requisitos, isso porque à medida que as expectativas dos usuários trazem consigo suas experiências e a experiência de uma pandemia pode mudar nossas relações como o espaço. Com base nos protocolos analisados, no entanto, percebe-se que os requisitos são comuns entre os documentos, muitos deles não são inéditos, mas naturalmente ganham mais importância na necessidade atual de controle de risco biológico. Justamente, por não serem requisitos em sua maioria inéditos, o trabalho também levanta a importância da criação de normas de desempenho específicos para ambientes educacionais, visto que os protocolos analisados delimitam requisitos já tratados na norma de desempenho já existente, NBR 15575/2013, no entanto tal norma trata de ambientes residenciais, sendo pertinente discutir tal tema em outras áreas.

Por fim, destaca-se que a maior parte dos requisitos englobam uso e ocupação, deixando evidente a necessidade de que ao levantarem programas de necessidades no início dos projetos, tal área deve receber a mesma importância que os requisitos funcionais recorrentemente mais tradicionais recebem. Se os protocolos como documentos normativos pouco acrescentam em ineditismo aos processos de projeto para futuros espaços, é importante 
destacar que enquanto experiência, a pandemia tende a gerar impacto nas percepções pessoais, e, para estudos futuros é pertinente avaliar a percepção dos usuários quanto ao desempenho esperado.

\section{Agradecimentos}

A Fapemig - Fundação de Amparo à Pesquisa do Estado de Minas Gerais pelo apoio na forma concessão de bolsas ao Programa de Pós-Graduação de Arquitetura e Urbanismo da Universidade Federal de Viçosa.

\section{Referências Bibliográficas}

ALRAOUF, A. The new normal or the forgotten normal: contesting COVID 19 impact on contemporary architecture and urbanism. In: International Journal or Architectural Research. vol 15, n.1, 2021, pp. 167-188.

ANDERY, P. R; STARLING, C.; MARTINS, R. Avaliação do processo de projeto em reformas de edificações de Universidade Pública. Gestão e Tecnologia de Projetos, São Paulo, v. 10, n. 1, p. 4965, jan./jun. 2015

BAKENS, W. PBB - Performance based building. 10DBMC-International Conference On Durability of Building Materials and Components. Anais. Lyon, France. April, 2005. p.17-20.

BRASIL. Ministério da Educação. Protocolo de biossegurança para retorno das atividades nas Instituições Federais de Ensino. Brasília, 2020. Disponível em: https://www.gov.br/mec/pt$\mathrm{br} /$ centrais-de-conteudo/campanhas-

1/coronavirus/CARTILHAPROTOCOLODEBIOSSEGURANAR101.pdf/@@download/file/CARTILHAPRO TOCOLODEBIOSSEGURANAR101.pdf.Acesso em 13/09/2020.

CARABIA, F. Precise diffuse limits: paradoxal architectures in the post Covid era. In Revista RITA 14 Revista de la Universidad de la Republica del Uruguay. Edicción especial, 2020.

COHEN, S. C.; CARDOSO, T. A. de O.; NAVARRO, M. B. M. de A., KLIGERMAN, D. C.. Habitação saudável e biossegurança: estratégias de análise dos fatores de risco em ambientes construídos. Saúde Debate. Rio de Janeiro, v. 43, n. 123, p. 1194-1204, out-dez 2019.

COUTINHO, L.; LIMA, A. C. Gestão de projeto em instituição federal de ensino superior: estudo de caso na Universidade Federal do Pará. Brasil - São Carlos, SP. 2009. In: SIMPÓSIO BRASILEIRO DE QUALIDADE DO PROJETO NO AMBIENTE CONSTRUÍDO. Anais São Carlos, 2009. 11 p

DUARTE, V. G.; NORONHA, M. P. Performance e arquitetura: uma transmutação conceitual a partir do estudo do edifício da Fundação Iberê Camargo, de Álvaro Siza. In: CONGRESSO INTERNACIONAL DO CURSO DE HISTÓRIA DA UFG/JATAÍ, 2., 2011, Jataí. Anais. Jataí: UFG, 2011.

ESTEVES, J. C. Planejamento e gestão do ambiente construído em universidades públicas. 2013. Dissertação (Mestrado em Engenharia Urbana) -Universidade Federal de São Carlos, São Carlos, 2013.

ESTEVES, J. C.; FALCOSKI, L. A. N. Gestão do processo de projetos em universidades públicas: Estudos de caso. Gestão de Tecnologia de Projetos, São Paulo, v. 8, n. 2, p. 67-87, jul./dez. 2013.

FALORUD, J. Envisioning a strategic framework for streamline building operation, sustainability and users's desease control. In: Journal of facilities management, December 2020. 
FOLIENTE, G. C. Developments in performance-based building codes and standard. Forest Products Journal 50(7):12-21 July 2000.

GIBSON, E. J. Working with the performance approach in building. CIB Report. Publication 64. Rotterdam. 1982.

IZUMI, T. et al. Managing and responding to pandemics in higher educational institutions: initial learning from COVID 19. In: International Journal of Disaster and Resilience in the Built Environment, vol. 12 , no. 1. 2021, pp. 51.66.

MEGAHED, E. e GHONEIM, E. Antivirus built environment: lessons learned from COVID 19 pandemic. In: Sustainable cities and Society, vol 21, oct. 2020, 9 p.

MEHAGED, E. e GHONEIM, E. Indoor air quality: rethinking rules of building design strategies in te post pandemic architecture. In: Environmental Research, n. 193, n. 110471, 2021.

MEHTA, V. The new proxemics: COVID 19, social distancing and social space. In Journal of Urban Design, vol. 6, 2020.

MELONE, M. E BONGO, S. Rethinking rules and social practices. The Design of urban spaces in the post COVID 19 lockdown. In: Journal of Land use, mobility and environment. Special Issue, 2020, pp. 333-341.

MOTTA, V. L. M. da. Gestão de projeto em empresa pública: estudo de caso da Universidade Federal Fluminense. Dissertação (Mestrado em Arquitetura). Universidade Federal do Rio de Janeiro, 2003.

PAPU, Sapna; PAL, Shreyasi. Braced for Impact: Architectural Praxis in a Post-Pandemic Society. Discover research from Advance: Social Sciences \& Humanities. Disponível em: https://advance.sagepub.com/articles/preprint/Braced_for_Impact_Architectural_Praxis_in_a_Pos t-Pandemic_Society/12196959/1. Acesso em 26/10/2020.

PARKER, L. The COVID 19 office in transition: cost efficiency and social responsibility business case. In: Accouting, Auditing \& Accountability Journal, vol. 33, n. 8 2020, pp. 1943-1987.

ROMANO F. V. Modelo de referência para o gerenciamento do processo de projeto integrado de edificações. Gestão \& Tecnologia de Projetos. Vol. 1, n.1, 2006.

SAADAT, S., RANTANI, D. e HUSSAIN, C. Environmental perspective of COVID 19. In: Science of the Total Environment, n. 728, 2020.

SANGIONI, L. A. ; PEREIRA, D. I. B.; VOGEL, F. S. F.; BOTTON, S. de A.. Princípios de biossegurança aplicados aos laboratórios de ensino universitário de microbiologia e parasitologia. Revista Ciência Rural, v.43, n.1, p.91-99. jan, 2013.

SEGATA, J. COVID-19, biossegurança e antropologia. Horizontes antropológicos. Porto Alegre, ano 26, n. 57, p. 275-313, maio/ago. 2020

SIMAS, C. M.; CARDOSO, T. A. de O.. Biossegurança e arquitetura em laboratórios de saúde pública. Pós. v.15 n.24, São Paulo, dezembro, 2008.

SILVA E.L. e MENEZES E.M. Metodologia da pesquisa e elaboração de dissertação. - Florianópolis: Departamento de Ciência da Informação da UFSC, 2005.

SINDUSCON-MG- Sindicato da Indústria da Construção Civil no Estado de Minas Gerais. Manual para contratação de projetos para o desempenho de edificações habitacionais. Belo Horizonte: SENAI Departamento Regional - MG Sinduscon-MG, 2016. 260 p.

SZIGETI, F. JASUJA, M. Performance based building: Conceptual Framework. In: International Council for Research and Innovation in Building and Construction - Development Foundation. 2005. 
Renata Soares Faria renata.resf@hotmail.com

Paulo Roberto Pereira Andery paulo@demc.ufmg.br
Os requisitos de projeto em contexto de pandemia: uma discussão sobre os espaços de ensino em instituições públicas

TAKEWAKI, I. New architectural viewpoint for enhacing society resilience for multiple risks including emerging COVID 19. In: Frontiers in Built Environment, vol 6, sept. 2020, 4 p.

Universidade Federal de Minas Gerais (UFMG). Protocolo de biossegurança, adequação do espaço físico e monitoramento da COVID-19 na UFMG. Belo Horizonte, 2020. Disponível em: https://ufmg.br/storage/7/a/8/d/7a8df00756a4b24203cb253915559e65_15955938800698_6806 22154.pdf. Acesso em 13 de outubro de 2020.

Universidade Federal de Minas Gerais (UFMG). Nota à Comunidade da UFMG. Belo Horizonte, 2021. Disponível em: https://ufmg.br/storage/9/a/c/c/9accd0b8861aa9e69773597e3b0aeb00_16194512801145_14478 97415.pdf. Acesso em 20 de maio de 2021.

Universidade do Porto. Recomendações para a atividade presencial na U. Porto. Porto, 2020. Disponível em: http://up.pt/COVID-19/wpcontent/uploads/sites/513/2020/10/Recomendacoes_retoma_atividadepresencia_15_09-2.pdf. Acesso em 13 de outubro e 2020.

Universidade Estadual de Campinas-UNICAMP. Cartilha COVID-19 - Orientações sanitárias para o enfrentamento da pandemia. Disponível em: https://www.unicamp.br/unicamp/cartilha-COVID19/orientacoes-sanitarias-para-o-enfrentamento-da-pandemia. Acesso em 13 de outubro e 2020.

VERONESE, A. Architecture pos COVID 19. Using proxemics in spatial design. In: Magazine del Festival dell Architetura, no. 52-53, 2020.

YIN, R. K. Estudo de caso: planejamento e métodos. Porto Alegre: Bookman, 2005. 212 p. 